\title{
Permanent Magnet Synchronous Motor Vector Control System Based on the Fuzzy PID Controller
}

\author{
Ruimin Qi ${ }^{\mathrm{a}}$, Guodong Zhang \\ Zheng Zhou University of Industrial Techinology College of Mechanical and Electrical \\ Engineering Zhengzhou, China \\ aqrm2007@126.com, bhangguodong1983@126.com
}

Keywords: Permanent magnet synchronous motor, Fuzzy PID control, Vector control

\begin{abstract}
Through the analysis of the mathematical model of permanent magnet synchronous motor (PMSM), the paper proposed the method of fuzzy PID controller, and applied to the speed controller of permanent magnet synchronous motor double closed loop vector control system, exactly implementing the speed controller of permanent magnet synchronous motor. Comparing with the traditional PID controller, this method gains favorable performance in the speed controller of permanent magnet synchronous motor.
\end{abstract}

\section{Introduction}

Permanent magnet synchronous motor use high-energy permanent magnets, it saves the excitation coil and brush, and it eliminates the influence of the mechanical transmission chain, it technical performance is better than that of brushless dc motor and induction servo motor, it has small size, low dissipation, high efficiency, good reliability and the characteristics of strong adaptability to the environment. The motor can achieve high performance control. So as a new generation of control motor, permanent magnet synchronous motor has become the preferred drive motor of AC servo system. In CNC machine tools, industrial robots, it get more and more widely used. it gets more and more widely used in electric drive system. But the permanent magnet synchronous motor is a multivariable, serious nonlinear and parameter time-varying and strong coupling control object, it is hard to use accurate mathematical model to describe the dynamic process of permanent magnet synchronous motor. Permanent magnet synchronous motor is affected by the load disturbance, and permanent magnet synchronous motor is affected by nonlinear, so its anti-interference ability is poor.

\section{Permanent magnet synchronous motor mathematical model}

The basic principle of permanent magnet synchronous motor vector control is that PMSM Stator current is decomposed into direct axis current component id and quartered axis current component iq, for permanent magnet synchronous motor, An effective vector control strategy is to keep straight axis component of stator current id is zero (id $=0$ ), and make electromagnetic torque and quartered axis component of stator current is proportional to the iq ,and can assure it get the maximum output torque with minimum current amplitude, and achieve good linear decoupling control effect.d - $\mathrm{q}$ axial model of permanent magnet synchronous motor voltage equation is:

$$
\left[\begin{array}{l}
u_{d} \\
u_{q}
\end{array}\right]=\left[\begin{array}{cc}
R_{s} & 0 \\
0 & R_{s}
\end{array}\right]\left[\begin{array}{l}
i_{d} \\
i_{q}
\end{array}\right]+\left[\begin{array}{cc}
\frac{d}{d t} & w_{r} \\
-w_{r} & \frac{d}{d t}
\end{array}\right]\left[\begin{array}{l}
\Psi_{d} \\
\Psi_{q}
\end{array}\right]
$$

flux equation of permanent magnet synchronous motor are as follows:

$$
\left[\begin{array}{l}
\Psi_{d} \\
\Psi_{q}
\end{array}\right]=\left[\begin{array}{cc}
L_{d} & 0 \\
0 & L_{q}
\end{array}\right]\left[\begin{array}{l}
i_{d} \\
i_{q}
\end{array}\right]+\left[\begin{array}{c}
\Psi_{f} \\
0
\end{array}\right]
$$


The electromagnetic torque of permanent magnet synchronous motor is:

$$
T_{e}=1.5 P\left[\Psi_{f} i_{q}+\left(L_{d}-L_{q}\right) i_{d} i_{q}\right]
$$

type, ud, uq is d, q axis stator voltage; RS is d, q axis stator three phase winding voltage; Ld, Lq is d axis, $\mathrm{q}$ axis stator winding inductance; $\mathrm{p}$ is motor logarithmic; $\psi \mathrm{f}$ is permanent magnet magnetic chain; $\omega r$ is the rotor angular velocity.

\section{Permanent magnet synchronous motor vector control system based on the fuzzy PID controller}

\subsection{The system structure}

On the basis of analysis of permanent magnet synchronous motor mathematical model, in this paper, design of the all-digital fuzzy vector control system structure model is shown in figure 1.

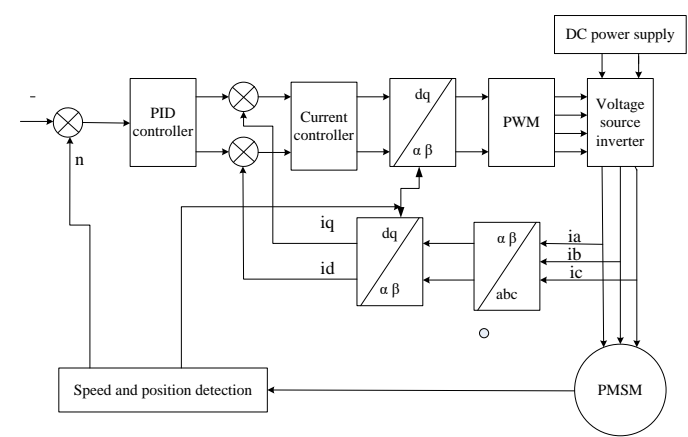

Figure 1 permanent magnet synchronous motor vector control system structure

The control system consists of a speed outer loop and two current inner loop,torque control can achieve by decoupling control of Current loop through id and iq. The effect of speed loop is to enhance system ability to resist load disturbance and determine operating performance of the system. Instead of the traditional PID controller on speed loop, Fuzzy PID controller is consider closed-loop vector control system as speed governor of the permanent magnet synchronous motor, Current controller also uses the PID controller. Speed control system adopts AC - DC - AC structure as voltage source type variable voltage variable frequency technology, PWM technology using space vector pulse width modulation method, the purpose is to reduce the harmonic component of inverter output current, harmonic loss and torque pulsation of motor, so that the permanent magnet synchronous motor gets amplitude constant circular magnetic field, it is the sinusoidal magnetic flux.

When system detected the three-phase stator current flow of permanent magnet synchronous motor, it must be transformed into the current component of rotor coordinates by Park and Charke. Charke transformation is as follows:

$$
\left[\begin{array}{l}
i_{o} \\
i_{B}
\end{array}\right]=\sqrt{\frac{2}{3}}\left[\begin{array}{ccc}
1 & -\frac{1}{2} & -\frac{1}{2} \\
0 & \frac{\sqrt{3}}{2} & -\frac{\sqrt{3}}{2}
\end{array}\right]\left[\begin{array}{l}
i_{a} \\
i_{b} \\
i_{c}
\end{array}\right]
$$

Park transformation is as follows:

$$
\left[\begin{array}{l}
i_{d} \\
i_{q}
\end{array}\right]=\left[\begin{array}{cc}
\cos \theta & \sin \theta \\
-\sin \theta & \cos \theta
\end{array}\right]\left[\begin{array}{l}
i_{o} \\
i_{B}
\end{array}\right]
$$

\subsection{Fuzzy PID controller design}

In order to achieve the real-time, high precision speed control of permanent magnet synchronous motor, combining traditional PID with fuzzy control, the system can adjust PID parameters kp,ki and kd online according to the different speed deviation and deviation rate using fuzzy reasoning strategy. Figure 1 is for fuzzy PID control system principle diagram. 
First, the system calculates the actual speed $n$ and the given speed $n_{r}$ deviation $e$ and the deviation change rate $e c$, after they are blurred, the blurred $\mathrm{E}$ and $\mathrm{EC}$, by the fuzzy reasoning and fuzzy control rules gets $\mathrm{k}_{\mathrm{p}}, \mathrm{k}_{\mathrm{i}}$ and $\mathrm{k}_{\mathrm{d}}$. The conventional PID controller parameters are modified online in the process of control, then the conventional PID controller outputs control object to adjust the motor speed.

Permanent magnet synchronous motor of the fuzzy control system structure is shown in figure 2.

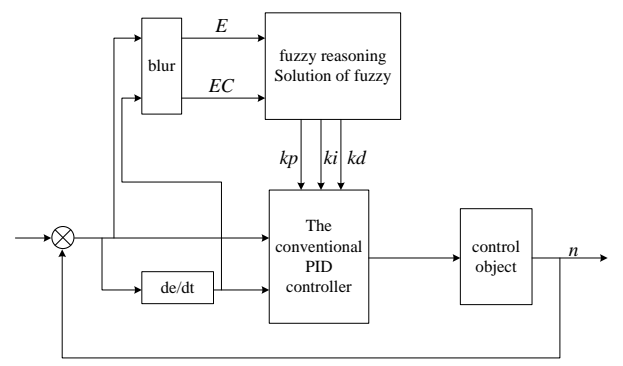

Figure 2 structure of fuzzy PID control system

Deviation $\mathrm{E}$ and the rate of deviation EC are described by seven states in a set, their fuzzy subset are $\mathrm{E}=\{\mathrm{NB}, \mathrm{NM}, \mathrm{NS}, \mathrm{Z}, \mathrm{PS}, \mathrm{PM}, \mathrm{PB}\}$ and $\mathrm{EC}=\{\mathrm{NB}, \mathrm{NM}, \mathrm{NS}, \mathrm{Z}, \mathrm{PS}, \mathrm{PM}, \mathrm{PB}\}$, also the subset of $\mathrm{kp}$, ki and kd are defined as $\{\mathrm{NB}, \mathrm{NM}, \mathrm{NS}, \mathrm{Z}, \mathrm{PS}, \mathrm{PM}, \mathrm{PB}$, in which $\mathrm{Z}$ stands for zero, PS is positive small, $\mathrm{PM}$ is positive middle, $\mathrm{PB}$ is positive big, on the contrary $\mathrm{NB}$ is negative big, $\mathrm{NM}$ is negative middle, $\mathrm{NS}$ is negative small. If $\mathrm{E}, \mathrm{EC}, \mathrm{kp}, \mathrm{ki}$ and $\mathrm{kd}$ is $\{-6,-5,-4,-3,-2,-1,0,+1,+2,+3,+4,+5,+6\}$, membership function gets from distribution function of triangle.

$k p$ 's function is to accelerate the response speed of system and improve the accuracy of the system. $k p$ is the greater, the faster the response speed, accuracy of the system is more the higher. But the system is prone to overshoot, even lead to system instability. Conversely kp is the smaller, response speed is slower, adjustment time becomes longer, the result accuracy will decrease reducing the static and dynamic performance of the system.

$k_{i}$ 's function is to eliminate the steady-state error of the system. The greater the $k_{i}$ the faster eliminate the steady-state error of the system. When $k_{i}$ is too small, the system steady-state error is difficult to eliminate, so, adjust the accuracy will be affected.

$k_{d}$ 's function is to improve the dynamic performance of the system, if it is too big, the system of regulating time will be extended,

According to the characteristics of permanent magnet synchronous motor speed control, we generalize $\mathrm{kp}$, ki and kd internal relation after fuzzy control rules, that is inputting $\mathrm{E}$ and EC after reasoning synthesis of the fuzzy control rules outputting variables of $\mathrm{k}_{\mathrm{p}}, \mathrm{k}_{\mathrm{i}}$ and $\mathrm{k}_{\mathrm{d}}$, and they are blurred operation converting into accurate speed value that actuators can accept.

Max-min synthesis of fuzzy reasoning using Mandani's CRI inference method, first from internal fuzzy relation, select "maximum and minimum" operation as a synthesis operation, finally derive fuzzy output value. The method used in the solution is the gravity center, which is the weighted average method. To realize real time control, to meet the requirements of system control, offline computing is used here. That is, the fuzzy control rules are converted to the control query table off-line, it is easy to realize the real-time control of the fuzzy controller through the look-up table, which can improve the response speed of the system.

\section{Conclusions}

The fuzzy PID controller replaced the traditional PID controller in the vector control system of PMSM. The controller as the speed regulator to control the speed of the motor. Simulation results show that this method had strong robustness and adaptability. And achieved an ideal effect, in order to realize the intelligent control system of permanent magnet synchronous motor, the feasible technical scheme is provided. 


\section{References}

[1] Limei Wang, Mingxiu Tian, Li Wang. Design of neural network fuzzy controller for permanent magnet synchronous motor[J]. Electric drive, 2006,36(8):34-37.

[2] Yanping Xu, Yanru Zhong, Hui Yang. Research on vector control and direct torque control of permanent magnet synchronous motor[J]. Power electronic technology, 2008,42(1):60-62

[3] Xiaofeng Gong, Qiwei Xue. Robust control of permanent magnet synchronous motor based on neural network and fuzzy algorithm[J]. Motor and control applications, 2005,32(3):14-17.

[4] Gao Y, Chen L, Ehsani M. Investigation of theeffectiveness of regenerative vraking for EV and HEV[C]//FutureTransportation Technology Conference \& Exposition. Costa Mesa, CA, USA: Electric and HybridElectric Vehicles, Hybrid Electric Control Systems,1999.

[5] Ehsani M, GAO Y,Butler K L.Application of electrically peaking hybrid(ELPH) propulsion system to a full size passenger car with simulated design verification[J].IEEE Transaction on Vehicular Technology,1999,48(6):1779-1881.

[6] Zhang Junzhi, Lu Xin, Zhang Pengjun, etal. Road test of hybrid electric bus with regenerative braking system[J]. Journal of Mechanical Engineering,2009,45(2):25-30. 